\title{
Sessile Lesion
}

National Cancer Institute

\section{Source}

National Cancer Institute. Sessile Lesion. NCI Thesaurus. Code C35935.

Attached directly by the base; not having an intervening stalk. 